\title{
Effects of Açai (Euterpe oleracea Mart.) berry preparation on metabolic parameters in a healthy overweight population: A pilot study
}

\author{
Jay K Udani ${ }^{1,2^{*}}$, Betsy B Singh ${ }^{1}$, Vijay J Singh ${ }^{1}$ and Marilyn L Barrett ${ }^{3}$
}

\begin{abstract}
Background: The purpose of this study was to evaluate the effect of açai fruit pulp on risk factors for metabolic disorders in overweight subjects. The açaí palm (Euterpe oleracea Mart.), which is native to South America, produces a small, black-purple fruit which is edible. The fruit has recently become popular as a functional food due to its antioxidant potential. Although several studies have been conducted in vitro and with animals, little is known about the potential health benefits in humans aside from an increase in plasma anti-oxidant capacity. Metabolic syndrome is a condition which is defined by a cluster of risk factors for cardiovascular disease and/or type-2 diabetes. Preliminary studies indicate that a reduction in reactive oxygen species can assist in the normalization of the metabolic pathways involved in this syndrome.
\end{abstract}

Methods: This was an open label pilot study conducted with 10 overweight adults (BMI $\geq 25 \mathrm{~kg} / \mathrm{m}^{2}$ and $\leq 30 \mathrm{~kg} /$ $\mathrm{m}^{2}$ ) who took $100 \mathrm{~g}$ açai pulp twice daily for 1 month. The study endpoints included levels of fasting plasma glucose, insulin, cholesterol, triglycerides, exhaled (breath) nitric oxide metabolites (eNO) and plasma levels of high sensitivity C-reactive protein (hs-CRP). The response of blood glucose, blood pressure and eNO to a standardized meal was determined at baseline and following the 30 day treatment.

Results: Compared to baseline, there were reductions in fasting glucose and insulin levels following the 30 day treatment (both $p<0.02)$. There was also a reduction in total cholesterol $(p=0.03)$, as well as borderline significant reductions in $\mathrm{LDL}$-cholesterol and the ratio of total cholesterol to HDL-cholesterol (both $p=0.051$ ). Compared to baseline, treatment with açai ameliorated the post-prandial increase in plasma glucose following the standardized meal, measured as the area under the curve $(p=0.047)$. There was no effect on blood pressure, hsCRP or eNO.

Conclusion: In this uncontrolled pilot study, consumption of açai fruit pulp reduced levels of selected markers of metabolic disease risk in overweight adults, indicating that further studies are warranted.

\section{Background}

People who are overweight, particularly those with excess central adipose tissue, are at risk of developing dysfunctions in lipid and glucose metabolism resulting in a propensity for cardiovascular disease and/or type- 2 diabetes. This cluster of symptoms, which includes elevated blood pressure, elevated fasting blood glucose levels, elevated triglycerides and reduced levels of high-

\footnotetext{
* Correspondence: jay.udani@medicusresearch.com

'Medicus Research LLC, Northridge, CA 91325, USA

Full list of author information is available at the end of the article
}

density lipoprotein cholesterol, has been defined as metabolic syndrome[1].

Oxidative stress, which is an imbalance between the generation of free radical species and the activity of anti-oxidant defense mechanisms, is thought to be one of the underlying mechanisms behind the risk of cardiovascular disease and diabetes associated with obesity[2]. Subjects who are obese are more likely to have higher levels of oxidative stress than those of normal weight. In addition, weight loss is associated with a decrease in oxidative stress[3]. Further, analysis of endogenous antioxidant protection in subjects with metabolic syndrome indicate that it is depressed[4]. And, subjects with

\section{() Biomed Central}


metabolic syndrome also tend to display an increase in oxidative damage, measured as elevated lipid peroxidation and elevated protein carbonyls[3]. Oxidative stress has also been shown to enhance insulin resistance and it has been suggested that antioxidant therapy may reduce insulin resistance in diabetic patients[4,5].

Diets which are high in fruits and vegetables, are reported to increase plasma antioxidant capacity[6]. In addition to vitamins $\mathrm{C}, \mathrm{E}$ and beta-carotene, fruits and vegetables contain phenolic compounds that contribute to their antioxidant capacity[7]. The inverse relationship between fruit and vegetable intake and the risk of cardiovascular diseases and diabetes has been associated with antioxidant capacity of these foods and in their phenolic content $[8,9]$. Preclinical studies have reported that polyphenolics compounds have beneficial effects on glucose absorption, insulin levels and lipid metabolism[10].

The fruit of the açaí palm (Euterpe oleracea Mart.), which is native to South America has recently become popular as a functional food due to its antioxidant potential[11]. The edible fruit is round, black-purple in color, about 1-inch $(25 \mathrm{~mm})$ in diameter and contains a single large seed. Macerating the pulp of the fruit produces a viscous liquid which is approximately $2.4 \%$ protein and 5.9\% lipid (by weight)[12]. Analysis of fatty acid composition reveals that monounsaturated oleic acid is the primary fat, present at $56.2 \%$, followed by palmitic (saturated fatty acid; 24.1\%) and linoleic acid (polyunsaturated; 12.5\%)[11]. Analysis of phenolics in the fruit revealed the presence of anthocyanin 3-glycosides, ferulic acid, epicatechin, p-hydroxy benzoic acid, gallic acid, protocatechuic acid, catechin, ellagic acid, vanillic acid, p-coumaric acid and gallotannins[12]. Cyanidin-3-monosaccharides are reported to be present in the fresh pulp at a concentration of $1040 \pm 58 \mathrm{mg} / \mathrm{L}$ [13]. More specifically, the glucosides cyanidin-3-rutinoside and cyanidin3 -glucose, were measured at concentrations of 1.93 and $1.17 \mathrm{mg} / \mathrm{g}$ dry weight, respectively, with a total anthocyanin content of $3.19 \mathrm{mg} / \mathrm{g}$ dry weight[11]. Açai pulp is reported to have an antioxidant capacity of $48.6 \mu \mathrm{mol}$ Trolox equivalents (TE)/ml as measured using the oxygen radical absorbance capacity (ORAC) assay[12]. Anthocyanins are generally considered to be the major contributors to the antioxidant activity of the pulp. However this concept has been challenged by a group of researchers who estimated the contribution of the anthocyanins to be just $10 \%$ of the total in vitro antioxidant capacity and suggested that other, unidentified, antioxidant constituents exist in the fruit[14]. This group of researchers compared the Total Oxidant Scavenging Capacity (TOSC) values for cyanidin-3-glucoside and cyanidin-3-rutoside to their corresponding concentrations in açaí preparations and found that the açaí preparations had significantly higher TOSC values than the calculated capacity due to constituent cyanidin glycosides.

In addition to the in vitro assays, the antioxidant potential of preparations of açaí pulp and juice has also been reported in animal and human studies. Experiments with rats revealed that a diet supplemented with $2 \%$ açai pulp (dry wt/wt) for 6 weeks caused a reduction in protein oxidation compared to control animals. Protein oxidation was measured as a decrease in carbonyl protein and an increase in protein sulfhydryl groups. There were also beneficial effects, compared to controls, on antioxidant enzyme activity, measured as an increase in serum paraoxonase, which is associated with prevention/inhibition of lipoprotein oxidation. In animals fed a hypercholesterolemic diet with or without açai pulp, there was a decrease in serum superoxide dismutase (SOD) activity compared to controls. SOD is an enzyme which is induced in response to oxidative stress and converts superoxide radicals into hydrogen peroxide[15]. In humans, plasma anti-oxidant capacity (measured using the ORAC assay) in humans increased up to 3 fold with a single dose of $7 \mathrm{ml}$ açaí pulp/kg body weight compared to the control beverage $(\mathrm{p}<0.01)$, with a $t$ max of 3 hours[16]. The maximum plasma concentration $\left(\mathrm{C}_{\max }\right)$ of total anthocyanins, measured as cyanidin3-glucoside was reached 2.2 hours after consumption of the pulp.This pharmacokinetic study included healthy volunteers, who were dosed after a 72 hour dietary washout phase and an overnight fast. The subjects consumed a diet low in antioxidants that excluded the majority of dietary polyphenolics. The antioxidant capacity was measured as the ratio of TE for each time point compared to baseline, divided by the dose volume administered to the subject.

As previously stated, reducing the production of reactive oxygen species is hypothesized to assist in the normalization of metabolic pathways that lead to the onset of diabetes, endothelial dysfunction and cardiovascular disease[2]. In a test of that hypothesis, this pilot study was designed to evaluate the effects of a proprietary preparation of açai pulp in overweight subjects who are at risk for developing metabolic syndrome. Several studies have been conducted on the effects on açai preparations in vitro and in animals, but little is known about its effects on humans. Epidemiological and experimental studies point to the potential benefits of antioxidants in ameliorating the risks of cardiovascular disease and diabetes type II, however the results from clinical studies with antioxidant vitamins have been equivocal. The study measured endpoints before and after administration of açai pulp for one month. Measurements included levels of fasting plasma glucose, insulin, cholesterol and triglycerides. Exhaled (breath) nitric oxide metabolites (eNO) and plasma levels of high sensitivity C-reactive 
protein (hs-CRP) were measured as indicators of inflammation. The response of blood glucose, blood pressure and $\mathrm{eNO}$ to a standardized meal was also determined.

\section{Materials and methods Investigational Product}

The preparation used in this study was Sambazon ${ }^{\circledR}$ Açai Smoothie Pack (Sambazon Inc, San Clemente, CA), a frozen product containing a puree of açai (Euterpe oleracea Mart.) pulp that is designed to be made into a smoothie. The açai pulp was pasteurized and manufactured in a GMP facility in Brazil. Initially a bulk pulp containing $14 \%$ dry açai solids was produced and this was diluted with water to produce the Smoothie Pack which contained $11 \%$ solids $(11 \mathrm{~g})$. The bulk pulp contained $6.42 \mathrm{~g}$ fatty acids per $100 \mathrm{~g}: 61.4 \%$ octadecenoic acids (18:1; including oleic acid), 20.8\% hexadecanoic acids (16:0; palmitic) and $11.2 \%$ octadecadienoic acids (18:2; linoleic acid). The bulk pulp also contained 3.5 $\mathrm{mg} / \mathrm{ml}$ total phenolics measured as gallic acid equivalents and $0.77 \mathrm{mg} / \mathrm{ml}$ total anthocyanins measured as cyanidin-3-glucoside equivalents (as analyzed by Brunswick Laboratories, MA). In vitro antioxidant capacity of the hydrophilic contents, measured as micromole Trolox equivalency using the ORAC assay, was $46 \mu$ mole TE/ml [17]. This activity accounted for $98.9 \%$ of the ORAC activity; only a little more than $1 \%$ of the in vitro antioxidant capacity was found in the lipid-soluble fraction. Nutrition analysis of the 100 g Pack performed by Silliker, Inc. Southern CA Laboratory (Cypress, CA) revealed the $100 \mathrm{~g}$ Pack contained 71.8 calories, $5.8 \mathrm{~g}$ total carbohydrate ( $<0.25 \mathrm{~g}$ sugars), $4.9 \mathrm{~g}$ total fat ( $1.1 \mathrm{~g}$ saturated fat), $5.33 \mathrm{~g}$ fiber and $1.0 \mathrm{~g}$ protein.

The participants were instructed to place the contents of the Sambazon ${ }^{\circledR}$ Açai Pulp into a Blender Bottle ${ }^{\circledR}$, adding water and up to $4 \mathrm{~g}$ (1 packet) of sugar as desired making a "smoothie". As a measurement of compliance, the participants took a photo of each smoothie and e-mailed the photo to the research coordinators before drinking. The dose was $100 \mathrm{~g}$ twice daily, taken in the morning and evening. A diary was kept noting whether each smoothie was consumed and the corresponding photo sent.

\section{Subjects}

Subjects were included if they were 18-65 years of age, had a BMI $\geq 25 \mathrm{~kg} / \mathrm{m}^{2}$ and $\leq 30 \mathrm{~kg} / \mathrm{m}^{2}$ and agreed to all study visits and procedures as well as not to initiate/ change any exercise or diet programs during the study. Females of child-bearing age agreed to use approved forms of birth control. Subjects were required to have a cell phone with a camera along with the ability to transmit photos and to agree to use their cell phone for study purposes. Subjects were excluded if they had any major systemic, inflammatory or chronic diseases, had an infection, used diabetic medications in the 4 weeks prior to the study, used insulin currently or in the past 3 years, had symptomatic hypoglycemia in the past month, used immunosuppressive drugs in the prior 5 years, smoked cigarettes, or abused alcohol/drugs. Females who were pregnant or lactating were also excluded. Subjects with a baseline exhaled nitric oxide (eNO) measurement of $>35 \mathrm{ppb}$ were also excluded. Intake of steroids, anti-inflammatory drugs, multi-vitamins and anti-oxidants were prohibited during the study.

\section{Study Design}

This was an open label pilot study conducted with 10 overweight adult men and women who took Sambazon ${ }^{\circledR}$ Açai pulp $100 \mathrm{~g}$ twice daily for 1 month. As this was a pilot study and there was no prior human data on the effects of the Açai product from which to perform a power calculation, the sample size was set at 10 . The study was conducted at the Staywell Research clinical research site located in Northridge, CA. and was monitored by the Medicus Research Contract Research Organization. Institutional Review Board approval was obtained from the Copernicus Group IRB (Cary, NC) prior to the initiation of any study related procedures. Good Clinical Practices (GCP) were followed throughout the study and all subjects gave informed consent according to GCP guidelines.

The clinical study began in October 2009 (first subject in) and lasted until December 2009 (last subject completed). The subjects in the study came to the research clinic for a total of 4 visits (V1-V4). The maximum treatment duration was 4 weeks. There was a window of \pm 2 days for V2, V3 and V4. The subjects were given a handout listing foods containing nitrates (for example bacon and hot dogs) and asked to avoid these foods for the duration of the study.

V1 was a screening visit during which the subjects were screened for inclusion and exclusion criteria, gave informed consent and medical history, received a physical examination, had a review of current medications, demographic assessment, urine collection (pregnancy test for females of child bearing age) and were dispensed standardized frozen foods which were the only foods to be consumed during the 24 hours prior to the next visit. V2 was the baseline visit for which the subjects arrived fasting (since mid-night the night before), having avoided exercise and alcohol for 24 hours and caffeine since $8 \mathrm{pm}$ the night before. They had a physical exam during which vital signs were noted along with anthropometric measures (body weight, height and circumferences of waist/hip). Baseline determinations were made of blood glucose (capillary), insulin, cholesterol (total 
cholesterol, HDL-cholesterol, LDL-cholesterol and triglycerides), exhaled (breath) nitric oxide metabolites (eNO) and high sensitivity C-reactive protein (hs-CRP). Blood glucose was measured using finger prick samples (Bayer Ascensia Contour Glucometer). Insulin was monitored using a chemilumiscent method on a DPC Immulyte Analyzer. Lipid levels and hs-CRP were determined using an Olympus AU 2700 Autoanalyzer. eNO was measured using a devise developed by Insight eNO System (previously Apieron Inc, Menlo Park, CA, now Aerocrine AB, Sweden). The devise measures eNO via an optical biosensor that undergoes a change in its optical absorbance when binding with nitric oxide[18].

Following the visit's baseline determinations, the subjects consumed a standardized meal (57 g carbohydrate, $50 \mathrm{~g}$ fat, $18 \mathrm{~g}$ protein, nitrate-free; Stouffer's Fettuccini Alfredo, Nestlé USA, Wilkes-Barre, PA). eNO was determined 1 hour and 2 hours after the meal. Blood pressure and blood glucose (capillary) levels were determined 30, 60, 90 and 120 minutes after the meal. After all tests were complete, the study products were dispensed as well as diaries (Daily dosing diary and 3day food recall diary). V3 was scheduled 2 weeks following visit 2 . During this visit, compliance was assessed by collecting product packaging dispensed at the previous visit. The diaries administered at the last visit were collected and new diaries were dispensed. Also dispensed were standardized frozen foods to be consumed during the 24 hours prior to next visit (V4). During V4 the measurements conducted during V2 were repeated. Compliance was again assessed and diaries administered at the last visit were collected.

\section{Statistical Analysis}

Excel 2003 (Microsoft Corp, Redmond WA) was used for data entry, validation, restructuring, calculating changes in variables over time, reorganizing and reformatting results, and preparing the graph. Statistical analyses (descriptive statistics and Student t tests) were performed using SPSS Base System ver. 17 (IBM SPSS Inc., Chicago IL.).

The percent changes in capillary blood glucose levels from time zero to 120 minutes after the meal were determined for each individual. The averages of the individual percent changes were calculated and plotted as minutes from time zero (baseline). The area under the curve (AUC) was calculated using the Trapezoidal Rule.

\section{Results}

The demographics of the ten participants in the study is given in Table 1 . Their body measurements did not change significantly over the month of the study. Threeday food recall diaries were collected at baseline and
Table 1 Participant Demographics

\begin{tabular}{ll}
\hline Number & $\mathbf{1 0}$ \\
\hline Age (years) & $18-46$ (mean 28.1) \\
\hline Sex & 5 men, 5 women \\
\hline Race & 9 Hispanic, 1 Caucasian \\
\hline Marital status & 5 single, 4 married, 1 divorced \\
\hline Body weight (lbs) & $173.0 \pm 18.1^{*}$ \\
\hline BMl & $27.4 \pm 1.8^{*}$ \\
\hline Waist/hip ratio & $0.86 \pm 0.06^{*}$ \\
\hline
\end{tabular}

* mean \pm standard deviation

after 4 weeks of treatment. Based on the assessment of macronutrient content (fat, protein, carbohydrates) and total caloric intake, the diet of the subjects did not change over the course of the study. The subjects took $100 \mathrm{~g}$ açai pulp twice daily for one month. Compliance, as measured using photographs of the prepared smoothies, was $100 \%$.

The subjects mean baseline fasting glucose level was $98.0 \pm 10.1 \mathrm{mg} / \mathrm{dl}$, which is on the upper edge of normal (70 to $99 \mathrm{mg} / \mathrm{dl}$ ) (Table 2)[1]. After one month administration of the açai pulp, the mean fasting glucose level decreased significantly to $92.8 \pm 10.9 \mathrm{mg} / \mathrm{dl}(\mathrm{p}=0.018)$. The mean plasma fasting insulin levels for the group decreased from $8.9 \pm 54 \mu \mathrm{U} / \mathrm{ml}$ at baseline, to $6.7 \pm 33$ $\mu \mathrm{U} / \mathrm{ml}(\mathrm{p}=0.017)$. (Table 2$)$

Consumption of açai reduced total cholesterol from $159 \pm 37 \mathrm{mg} / \mathrm{dl}$ to $142 \pm 28 \mathrm{mg} / \mathrm{dl}(\mathrm{p}=0.03)$.

Table 2 Measurements before and after administration of açai pulp

\begin{tabular}{|c|c|c|c|c|}
\hline Measurement & Time & Mean & Std. Deviation & Sig. \\
\hline \multirow[t]{2}{*}{ Fasting Glucose (mg/dl) } & Baseline & 98.0 & 10.1 & .018 \\
\hline & Day 30 & 92.8 & 10.9 & \\
\hline \multirow[t]{2}{*}{ Insulin $(\mu \mathrm{U} / \mathrm{ml})$} & Baseline & 8.92 & 5.4 & .017 \\
\hline & Day 30 & 6.68 & 3.3 & \\
\hline \multirow[t]{2}{*}{ Serum Cholesterol (mg/dl) } & Baseline & 159.2 & 37.4 & .030 \\
\hline & Day 30 & 141.8 & 28.3 & \\
\hline \multirow[t]{2}{*}{ Cholesterol Ratio } & Baseline & 3.79 & 1.0 & .051 \\
\hline & Day 30 & 3.42 & 0.9 & \\
\hline \multirow[t]{2}{*}{ VLDL (mg/dl) } & Baseline & 26.2 & 13.5 & .111 \\
\hline & Day 30 & 20.9 & 8.3 & \\
\hline \multirow[t]{2}{*}{$\mathrm{LDL}(\mathrm{mg} / \mathrm{dl})$} & Baseline & 90.1 & 29.1 & .051 \\
\hline & Day 30 & 78.1 & 25.3 & \\
\hline \multirow[t]{2}{*}{ HDL (mg/dl) } & Baseline & 42.9 & 8.4 & .953 \\
\hline & Day 30 & 42.8 & 9.3 & \\
\hline \multirow[t]{2}{*}{ Triglycerides (mg/dl) } & Baseline & 130.8 & 67.3 & .116 \\
\hline & Day 30 & 104.2 & 41.6 & \\
\hline
\end{tabular}

Measurements of glucose, insulin and lipid levels before and after administration of Sambazon açai for 30 days (given as means and standard deviations) were compared using paired t-tests to determine the significance of the change from baseline. 
Consumption of açai also reduced the levels of low density lipoprotein (LDL)-cholesterol from slightly elevated to within the optimal range $(p=0.51)$. Levels of high density lipoprotein (HDL)-cholesterol did not change significantly following intake of açai. The ratio of total cholesterol to HDL-cholesterol, obtained by dividing the HDL cholesterol level into the total cholesterol, was reduced from $3.79 \pm 1.0$ at baseline to $3.42 \pm 0.9$ after treatment $(\mathrm{p}=0.051)$. There was no significant change over time in levels of very low density lipoprotein (VLDL) cholesterol or triglycerides (Table 2).

The mean baseline measurement for highly sensitive C-reactive protein (hs-CRP) was $2.7 \pm 3.0 \mathrm{mg} / \mathrm{L}$ and did not change significantly following administration of açai.

The effects of consumption of a standardized meal (57 g carbohydrate, $50 \mathrm{~g}$ fat, $18 \mathrm{~g}$ protein, nitrate-free) on plasma glucose, mean exhaled nitric oxide (eNO) and blood pressure were determined before (baseline) and after 30 days of consumption of açai pulp. The averages of individual percent changes in capillary blood glucose levels from time zero to 120 minutes after the meal are plotted in Figure 1. At the baseline visit, the postprandial glucose levels peaked at 60 minutes, with an increase of $14.7 \%$. After 30 days of consumption of açaí, the percent change from baseline at 60 minutes was only $4.7 \%$. The glucose area under the curve (AUC) measurement for the baseline visit was $205.6 \pm 18.6$ and after 30 days of açaí was $189.7 \pm 26.3$ (mean \pm standard deviation). The difference was significant ( $p=0.047)$. Thus, consumption of açai pulp for 30 days significantly reduced the post-prandial increases in glucose levels following the standardized meal. There were no significant

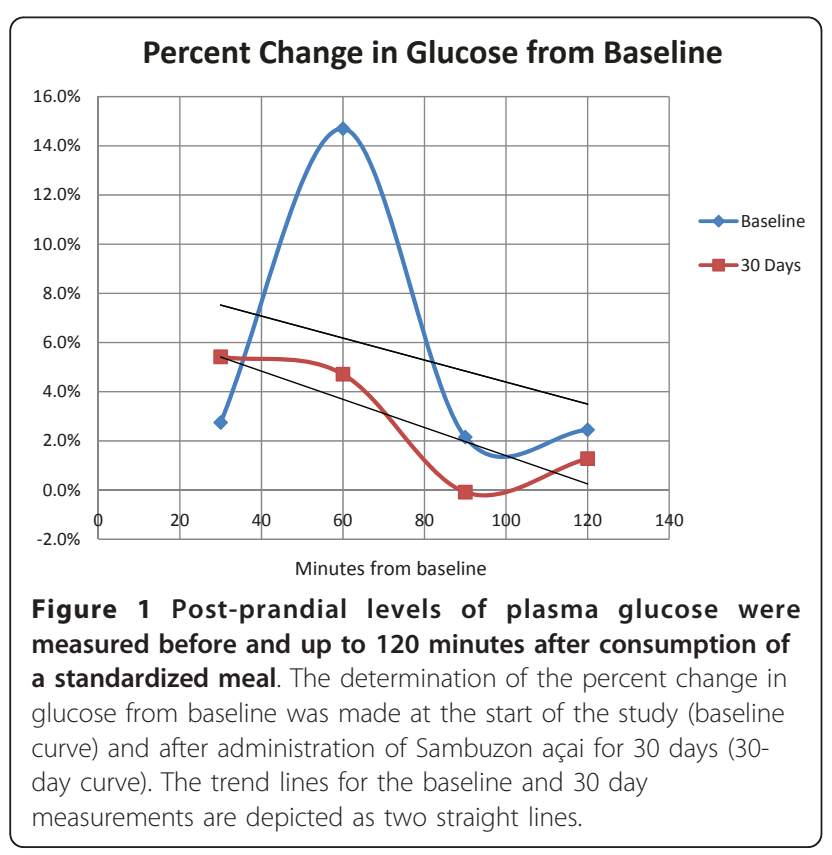

changes in blood pressure or in eNO. Mean baseline blood pressures were $119 \pm 7 \mathrm{mmHg}$ systolic and $72 \pm$ $9 \mathrm{mmHg}$ diastolic at baseline. The mean exhaled nitric oxide (eNO) level at baseline was $17.5 \pm 7.6 \mathrm{ppb}$, within the normal range of less than $25 \mathrm{ppb}$.

Açai pulp was safely consumed. There were no adverse events or changes in vital signs (body temperature, pulse or respiratory rate).

\section{Discussion}

According to the American Heart Association[19], a BMI of $25 \mathrm{~kg} / \mathrm{m}^{2}$ corresponds to about 10 percent over ideal body weight. People with BMIs in this range are considered to have an increased risk of developing dysfunctions in glucose/insulin levels and lipid metabolism. The subjects in this study had a mean BMI of 27.4 and were categorized as overweight (BMI 25 to 29.9). Consumption of Sambazon ${ }^{\circledR}$ Açai by this population, reduced plasma levels of fasting glucose, insulin and total cholesterol. Consumption of Sambazon ${ }^{\circledR}$ Açai also reduced the post-prandial increase in plasma glucose following a meal.

Epidemiologic studies on the prevention of diabetes have shown that overweight subjects randomized to various lifestyle interventions who demonstrated reductions in fasting glucose of $4 \mathrm{mg} / \mathrm{dL}$ (3.6\%) and in cholesterol of $5 \mathrm{mg} / \mathrm{dL}(2.3 \%)$ had a significant reduction $(58 \%)$ in the risk of becoming diabetic[20]. In this study, the reductions in fasting glucose and total cholesterol compared to baseline were $5.3 \%$ and $10.6 \%$. These reductions are greater than those deemed necessary for a change in risk status.

The potential effects of other anthocyanin-rich preparations on glucose levels in subjects with ether diabetes type 2 or metabolic syndrome have been tested clinically. Choke berry (Aronia melanocarpa) juice (200 $\mathrm{mls}$ ) given to subjects with type 2 diabetes $(200 \mathrm{ml} /$ day for 3 months) reduced fasting glucose levels $(13.3 \pm 4.5$ to $9.1 \pm 3.0 \mathrm{mmol} / \mathrm{l}$ ) and hemoglobin (Hb)A1c levels $(9.3 \pm 2.2$ to $7.5 \pm 1.3)$ compared to baseline (both $\mathrm{p}<$ 0.001 )[21]. However, another study in which an extract of choke berry $(3 \times 100 \mathrm{mg} /$ day $)$ was given to $25 \mathrm{sub}$ jects with metabolic syndrome for 2 months, did not show any effect on fasting plasma glucose levels (baseline $92.9 \pm 11.0 \mathrm{mg} / \mathrm{dl}$ )[22]. A preparation of concentrated sour cherry (Prunus cerasus) juice (40 g/day for 6 weeks) given to 17 women with diabetes type 2 resulted in significantly reduced $\mathrm{HbA1c}$ levels compared to baseline $(7.9 \pm 1.6$ to $7.5 \pm 1.2 ; \mathrm{p}<0.05)$ but no significant reduction in fasting glucose levels (baseline $158.3 \pm 43.4$ $\mathrm{mg} / \mathrm{dl})$ [23].

The possible effects of anthocyanins on diabetes as well as possible mechanisms of action have been explored in animal models. A bilberry extract added to 
the diet (10 g anthocyanins/ $\mathrm{kg}$ diet) of male KK-A $\gamma$ mice (a type 2 diabetic model) for 5 weeks ameliorated hyperglycemia and increased insulin sensitivity compared to control animals. In this study, stimulation of AMP-activated protein kinase was measured in white adipose tissue, skeletal muscle and the liver. This effect was accompanied by an upregulation of glucose transporter 4 in adipose tissue and muscle, and a suppression of glucose production and lipid content in the liver[24]. A black soybean seed coat preparation, delivering a dose of $50 \mathrm{mg}$ anthocyanins $/ \mathrm{kg}$ by gavage for 30 days, was reported to increase expression of glucose transporter 4 proteins in skeletal muscle and heart tissue in streptozotocin-induced diabetic rats[25]. Purified cyanidin 3-glucoside (2 $\mathrm{g} / \mathrm{kg}$ diet for 5 weeks) ameliorated hyperglycemia and increased insulin sensitivity in diabetic mice. The authors reported that cyanidin 3-glucoside upregulated glucose transporter 4 and down regulated retinol binding protein 4 expression[26].

In the present study, total and LDL cholesterol were reduced as well as the ratio of total cholesterol to HDLcholesterol. A reduction in total and LDL-cholesterol coupled with an increase in HDL-cholesterol is considered to be a step towards prevention of cardiovascular disease. The results of this study are in line with those reported in a rat study in which açai pulp reduced total and non-HDL cholesterol in treated animals compared to controls. In this study, the animals were fed a hypercholesterolemic diet with and without $2 \%$ açaí (dry $w t / w t)$ for 6 weeks[15]. An extract of choke berry $(3 \times$ $100 \mathrm{mg} /$ day) given to 25 subjects with metabolic syndrome for 2 months significantly decreased levels of total cholesterol, LDL and triglycerides compared to baseline, while HDL levels did not change[22]. However, the previously mentioned preparation of concentrated sour cherry juice ( $40 \mathrm{~g} /$ day for 6 weeks) given to women with diabetes type 2 did not significantly alter lipid levels[23].

Treatment with açai did not affect blood pressure in this study. An effect on blood pressure was suggested by an in vitro study conducted using an extract of açai fruit (injections of 10 to $100 \mathrm{mg}$ extract) added to rat mesenteric vascular bed previously contracted with norepinephrine. The study demonstrated that açai had an endothelium-dependent vasodilator effect due to effects on production of nitric oxide[27].

C-reactive protein (CRP) is one of the acute phase proteins that increases during systemic inflammation and measuring CRP levels in the blood is useful as an indicator of cardiovascular disease risk. An effect of anthocyanins on CRP in has not been established in previous clinical studies. This was also the case in a recently reported 2 month study in which an extract of choke berry $(3 \times 100 \mathrm{mg} /$ day $)$ was given to 25 subjects with metabolic syndrome for 2 months[22]. In accordance with previous results, this study did not demonstrate any significant change in levels of hs-CRP following administration of açai.

Exhaled nitric oxide (eNO) is an indicator of airway inflammation. There was no indication of airway inflammation in subjects in this study at baseline and no increase in eNO following the standardized meal. There is a report of an increase in eNO following a high fat meal (74 $\mathrm{g}$ fat; $1 \mathrm{~g}$ fat $/ \mathrm{kg}$ body weight) in healthy subjects[28]. However that finding was not repeated in this study.

Açai pulp was safely consumed in this study at a dose of $100 \mathrm{~g}$ twice daily for one month. Experiments with mice found that doses of 3.3 to $16.7 \mathrm{~g}$ açaí pulp per $\mathrm{kg}$ body weight, given i.p. once or daily for 14 consecutive days, did not cause any genotoxic effects[29].

This was an open label, uncontrolled, pilot study designed to explore the potential effects of Sambazon ${ }^{\circledR}$ Açai on risk factors for diabetes and cardiovascular disease. The limitations of this study are a lack of a blinding, a placebo control and the small sample population. This was an exploratory study, and as the results are positive, further studies placebo-controlled studies with a larger study population are warranted.

\section{Conclusions}

In this uncontrolled pilot study, consuming $200 \mathrm{~g}$ per day of Sambazon ${ }^{\circledR}$ Açai for 1 month reduced fasting levels of plasma glucose, insulin, and total cholesterol compared to baseline levels in a cohort of 10 overweight adults. Administration of Açai for 30 days also attenuated the post-prandial glucose response (AUC) following a standardized meal compared to the pre-treatment response. Sambazon ${ }^{\circledR}$ Açai was administered safely, without adverse events. The results of this study suggest that conducting a larger placebo-controlled trial to determine the effects of acai on risk factors for chronic disease is warranted.

\section{Acknowledgements}

Medicus Research would like to thank Sambazon Inc, of San Clemente, CA, for supporting this clinical trial.

\section{Author details}

${ }^{1}$ Medicus Research LLC, Northridge, CA 91325, USA. ${ }^{2}$ UCLA School of

Medicine, Department of Medicine, Los Angeles, CA 90024, USA.

${ }^{3}$ Pharmacognosy Consulting, Mill Valley, CA 94941, USA.

\section{Authors' contributions}

JKU conceptualized the study and was the Principal Investigator. BBS also participated in the design of the study. BBS and VJS performed the analysis. $J K U, B B S$ and MLB contributed to writing the manuscript. All authors have read and approved the final manuscript.

\section{Competing interests}

The authors declare that they have no competing interests. 
Received: 22 April 2010 Accepted: 12 May 2011 Published: 12 May 2011

\section{References}

1. Alberti KG, Eckel RH, Grundy SM, Zimmet PZ, Cleeman Jl, Donato KA, et al: Harmonizing the metabolic syndrome: a joint interim statement of the International Diabetes Federation Task Force on Epidemiology and Prevention; National Heart, Lung, and Blood Institute; American Heart Association; World Heart Federation; International Atherosclerosis Society; and International Association for the Study of Obesity. Circulation 2009, 120:1640-1645.

2. Grattagliano I, Palmieri VO, Portincasa P, Moschetta A, Palasciano G: Oxidative stress-induced risk factors associated with the metabolic syndrome: a unifying hypothesis. J Nutr Biochem 2008, 19:491-504.

3. Vincent HK, Taylor AG: Biomarkers and potential mechanisms of obesityinduced oxidant stress in humans. Int J Obes 2006, 30(3):400-418.

4. Roberts CK, Sindhu KK: Oxidative stress and metabolic syndrome. Life SCi 2009, 84:705-712.

5. Ando K, Fujita T: Metabolic syndrome and oxidative stress. Free Radic Biol Med 2009, 47:213-218.

6. Cao G, Booth SL, Sadowski JA, Prior RL: Increases in human plasma antioxidant capacity after consumption of controlled diets high in fruit and vegetables. Am J Clin Nutr 1998, 68:1081-1087.

7. Cao G, Russell RM, Lischner N, Prior RL: Serum antioxidant capacity is increased by consumption of strawberries, spinach, red wine or vitamin C in elderly women. J Nutr 1998, 128:2383-2390.

8. Fernandez-Panchon MS, Villano D, Troncoso AM, Garcia-Parrilla MC: Antioxidant activity of phenolic compounds: from in vitro results to in vivo evidence. Crit Rev Food Sci Nutr 2008, 48:649-671.

9. Arts IC, Hollman PC: Polyphenols and disease risk in epidemiologic studies. Am J Clin Nutr 2005, 81:317S-325S.

10. Dembinska-Kiec A, Mykkanen O, Kiec-Wilk B, Mykkanen H: Antioxidant phytochemicals against type 2 diabetes. Br J Nutr 2008, 99(E Suppl 1): ES109-ES117.

11. Schauss AG, Wu X, Prior RL, Ou B, Patel D, Huang D, et al: Phytochemical and nutrient composition of the freeze-dried amazonian palm berry, Euterpe oleraceae mart. (acai). J Agric Food Chem 2006, 54:8598-8603.

12. Del Pozo-Insfran D, Brenes CH, Talcott ST: Phytochemical composition and pigment stability of Acai (Euterpe oleracea Mart.). J Agric Food Chem 2004, 52:1539-1545.

13. Del Pozo-Insfran D, Percival SS, Talcott ST: Acai (Euterpe oleracea Mart.) polyphenolics in their glycoside and aglycone forms induce apoptosis of HL-60 leukemia cells. J Agric Food Chem 2006, 54:1222-1229.

14. Lichtenthaler R, Rodrigues RB, Maia JG, Papagiannopoulos M, Fabricius H, Marx F: Total oxidant scavenging capacities of Euterpe oleracea Mart. (Acai) fruits. Int J Food Sci Nutr 2005, 56:53-64.

15. Oliveira de SM, Silva M, Silva ME, de Paula OR, Pedrosa ML: Diet supplementation with acai (Euterpe oleracea Mart.) pulp improves biomarkers of oxidative stress and the serum lipid profile in rats. Nutrition 2010, 26(7-8):804-810, Epub 2009 Dec 22.

16. Mertens-Talcott SU, Rios J, Jilma-Stohlawetz P, Pacheco-Palencia LA, Meibohm B, Talcott ST, et al: Pharmacokinetics of anthocyanins and antioxidant effects after the consumption of anthocyanin-rich acai juice and pulp (Euterpe oleracea Mart.) in human healthy volunteers. J Agric Food Chem 2008, 56:7796-7802

17. Ou B, Hampsch-Woodill M, Prior RL: Development and validation of an improved oxygen radical absorbance capacity assay using fluorescein as the fluorescent probe. J Agric Food Chem 2001, 49:4619-4626.

18. Malmstrom RE, Tornberg DC, Settergren G, Liska J, Angdin M, Lundberg JO, et al: Endogenous nitric oxide release by vasoactive drugs monitored in exhaled air. Am J Respir Crit Care Med 2003, 168:114-120.

19. American Heart Association. Body composition tests. 2010 [http://www. americanheart.org/presenter.jhtml?identifier=4489], Ref Type: Online Source.

20. Tuomilehto J, Lindstrom J, Eriksson JG, Valle TT, Hamalainen H, llanneParikka P, et al: Prevention of type 2 diabetes mellitus by changes in lifestyle among subjects with impaired glucose tolerance. $N$ Engl J Med 2001, 344:1343-1350

21. Simeonov SB, Botushanov NP, Karahanian EB, Pavlova MB, Husianitis HK, Troev DM: Effects of Aronia melanocarpa juice as part of the dietary regimen in patients with diabetes mellitus. Folia Med (Plovdiv) 2002, 44:20-23.
22. Broncel M, Kozirog M, Duchnowicz P, Koter-Michalak M, Sikora J, Chojnowska-Jezierska J: Aronia melanocarpa extract reduces blood pressure, serum endothelin, lipid, and oxidative stress marker levels in patients with metabolic syndrome. Med Sci Monit 2010, 16:CR28-CR34.

23. Ataie-Jafari A, Hosseini S, Karimi F, Pajouhi M: Effects of sour cherry juice on blood glucose and some cardiovascular risk factors improvements in diabetic women: A pilot study. Nutrition \& Food Science 2008, 38:355-360

24. Takikawa M, Inoue S, Horio F, Tsuda T: Dietary anthocyanin-rich bilberry extract ameliorates hyperglycemia and insulin sensitivity via activation of AMP-activated protein kinase in diabetic mice. J Nutr 2010, 140:527-533.

25. Nizamutdinova IT, Jin YC, Chung Jl, Shin SC, Lee SJ, Seo HG, et al: The antidiabetic effect of anthocyanins in streptozotocin-induced diabetic rats through glucose transporter 4 regulation and prevention of insulin resistance and pancreatic apoptosis. Mol Nutr Food Res 2009, 53:1419-1429.

26. Sasaki R, Nishimura N, Hoshino H, Isa Y, Kadowaki M, Ichi T, et al: Cyanidin 3-glucoside ameliorates hyperglycemia and insulin sensitivity due to downregulation of retinol binding protein 4 expression in diabetic mice. Biochem Pharmacol 2007, 74:1619-1627.

27. Rocha AP, Carvalho LC, Sousa MA, Madeira SV, Sousa PJ, Tano T, et al: Endothelium-dependent vasodilator effect of Euterpe oleracea Mart. (Acai) extracts in mesenteric vascular bed of the rat. Vascul Pharmacol 2007, 46:97-104.

28. Rosenkranz SK, Townsend DK, Steffens SE, Harms CA: Effects of a high-fat meal on pulmonary function in healthy subjects. Eur J Appl Physiol 2010 109(3):499-506, Epub 2010 Feb 18.

29. Ribeiro JC, Antunes LM, Aissa AF, Darin JD, De Rosso W, Mercadante AZ, et al: Evaluation of the genotoxic and antigenotoxic effects after acute and subacute treatments with acai pulp (Euterpe oleracea Mart.) on mice using the erythrocytes micronucleus test and the comet assay. Mutat Res 2010, 695(1-2):22-28, Epub 2009 Nov 3.

doi:10.1186/1475-2891-10-45

Cite this article as: Udani et al.: Effects of Açai (Euterpe oleracea Mart.) berry preparation on metabolic parameters in a healthy overweight population: A pilot study. Nutrition Journal 2011 10:45

\section{Submit your next manuscript to BioMed Central and take full advantage of:}

- Convenient online submission

- Thorough peer review

- No space constraints or color figure charges

- Immediate publication on acceptance

- Inclusion in PubMed, CAS, Scopus and Google Scholar

- Research which is freely available for redistribution
Ciomed Central 